\title{
On the Importance of Recording Microforms and Digitised Versions Produced for Preservation on the International Level, with a Focus on Standards
}

by WERNER SCHWARTZ

\section{SURROGATES \& PRESERVATION}

When we think about preserving our cultural heritage the first thing that comes to mind is how to find ways to properly store and protect the original works of art, literature and science. Our aim is to save them for our time and for generations to come. We wish to restore them in such a way that their original structure and content is respected and remains unaltered while the material is strengthened to withstand the pressure exacted by use, climate and many other hazards. Very notable aims. Reality, however, is quick to bring disillusion. User demand far exceeds our possibilities to sufficiently prepare the original items or even to restore them diligently enough not to alter their originality. True restoration is bound to consume resources and time to such an extent that we cannot but treat only a relatively small number of items.

When dealing with library holdings, reformatting their contents to a surrogate support has therefore been viewed as a convenient way of preservation. Photography and microfilming in particular made it possible to save written or printed text and images by copying them to another support. It is true that the original item will not receive any special attention; it might even be exposed to some unwarranted stress while being processed. But as soon as the content has been reformatted to microfilm there is no need anymore to touch the original, which will thus be saved from further degradation caused by use.

The researcher as user of reformatted works will only accept a surrogate as a replacement if the true image of the original has been conveyed. Based on the image he can relate his citations or other references to the surrogate as though he was holding the original item in his hands. The microfilm and any second-generation reproduction made from it will always fulfil this condition. The digitised document must offer the image, if it is to be considered a preservation surrogate.

With the recent development of information technology this new technique of reformatting has become available. Digitisation lends itself not only to the production of an image of the original, it also provides all sorts of added features including the creation 
of a searchable text file, indexing and remote use by publishing an electronic document on the internet. There it is open to reciprocal hyperlinking with other online resources. The potential of remote usage, the ease of accessibility and the digital add-ons have tended to make digitisation the method of reformatting preferred by librarians as well as researchers. With the focus on improving online access to a document hitherto accessible on paper only, they almost lost sight of the aim to preserve the original's content. Instead the preservation of electronic documents quite naturally imposed itself as the new and so far untackled task of libraries. [1]

\section{Access}

In terms of user access and added value the digitised document is undoubtedly superior to the microfilm surrogate; at least in those parts of the world where the necessary IT infrastructure is readily available. In other parts, however, the sophisticated network capacities required for convenient access to digitised documents may not be there for some time to come. Here the older but very stable and widely used technology of microphotography - in principle - still has some advantages over the digital. The relative ease of producing reader copies on paper or in microform provides the technical basis for widespread surrogate use wherever it is requested. However, just as electronic equipment is needed to use the digital surrogate, users of microfilms must have microfilm readers at their disposal. It is no surprise to anyone who has followed the development of librarianship over the last dozen years that investment in equipment has focussed very much on all sorts of computers and related appliances. There is no exception to this rule, when we look at the less industrialised and less well-off countries. As a result, a growing shortage in basic microfilm equipment is rendering use of this kind of reliable surrogate increasingly difficult. This is especially true for those countries where the combined effect of limited resources and lack of stable networks join to makes the use of digitised documents even more difficult.

\section{Preservation}

We have already touched on the problem posed by electronic documents when we ask how to preserve them over time. Other speakers in this conference will discuss the serious questions involved. Microfilm on the other hand requires rather unsophisticated means to be properly stored over a long period of time. If established international standards are observed in production and storage, we can be sure to preserve the original work's contents by this surrogate not only for decades but also for centuries. It's true that the quality of microfilm in terms of resolution and colour cannot match the state-of-theart possibilities of the digital surrogate. When making choices we therefore have to ask what the aims of reformatting are in every particular case. This, and the expected frequency of use of the surrogate must determine which medium we chose. Both are open for conversion into the other medium. Microfilm can be scanned to produce digital 
images, and digital images can be used to produce output on microfilm. This secondary reformatting may gain increased importance in the future, especially for works that are in relatively low demand. But in either case we cannot pretend to reformat for preservation when in reality we produce a new kind of surrogate from the other, since a second generation copy will always be less accurate than the first.

\section{WHY IS IT IMPORTANT TO TELL OTHERS THAT YOU DIGITISED OR MICROFILMED A BOOK?}

Reformatting is a costly business no matter what type of surrogate you chose. You will have to make a considerable investment when you want to reproduce the original in high quality, provide access copies of different kinds, and store them and the first generation surrogate in a way that promises 'permanent access'. If reformatting is done by a commercial enterprise, the announcement that a certain work has been produced in surrogate will discourage competitors in the market to publish this same work. Libraries and other institutions of the non-commercial sphere may not have any aim to make profit in this field, but they may be trying to recover investment by revenue from subscriptions paid for access to surrogates. They, too, have a quasi-economic interest to make the existence of their surrogate known as widely as possible.

Libraries and similar institutions, however, have a more important reason than the economic one. It's their responsibility to preserve works of all kind for the present and for future generations. They have accepted this responsibility as a truly global one, not confined to works from their own country or in their language. The need to preserve the printed heritage in particular has been felt to be most urgent in view of its possible loss caused by paper deterioration. Looking at the cost involved in merely preserving the contents of threatened works by reformatting to surrogate, it is evident that no single library can cope with this task single-handedly. Some sort of coordinated approach must be followed to ever-direct limited resources to reformat works that have hitherto remained untreated.

\section{THE GENESIS OF INTERNATIONAL COOPERATION IN BUILDING A REGISTER OF SURROGATES}

This is precisely the idea underlying national registers of reformatted works, registers that ultimately merge into international registers. To my knowledge, the National Register of Microform Masters (Register, 1965-1984) is the first such endeavour. The 
Library of Congress published it in many volumes between 1965 and 1984. American libraries recognised that reformatting to microform can not only enhance accessibility of information but also play a major part in preservation, when duplication is avoided by projects which are working in parallel. Soon funding bodies reacted to this and gave their support to programmes of systematic microfilming while insisting that individual items be recorded. In the eighties, bibliographic databases were built up to record or include information on surrogates. The register of microform masters was converted to machine readable form [2]. Encouraged by the American library community and often financially supported by the Commission on Preservation and Access (CPA) [3], similar initiatives were undertaken in France, the United Kingdom and a number of other countries. One of the best-known examples is the programme of microfilming and creating a national register of preservation masters in the United Kingdom, which was funded by the Andrew W. Mellon Foundation.

In Europe systematic reformatting to microform had by then become the preferred choice of major preservation programmes. However, European librarians in one aspect had a more cautious attitude than their American colleagues, who occasionally took the surrogate as full replacement of the original. The Americans put their trust in the life expectancy of the microform to the extent that they felt justified to discard the original; an approach that was, though rarely, emulated in Europe [4]

The more conservative attitude of European libraries on the other hand resulted in the rather late recognition of the paramount importance of recording all microfilmed items. With the original item retained, some considered the microfilm little more than a secondary option. In spite of developments during the last decade to this day there still is no sufficient awareness of the fact that only a coordinated approach in reformatting can help to preserve a significant portion of the world's printed heritage [5].

In 1990 the European Register of Microform Masters (EROMM) was launched as one of the first library projects co-funded by the European Union. The project's aim was to create a database for recording all items that had been reformatted to microform in Europe. It was intended as an instrument of coordination and to help avoid duplication of effort; no book should be microfilmed twice. Instead libraries should use their limited resources to reformat items that had not been treated so far. In this endeavour the project won the support of the European Union, and the Commission on Preservation and Access in the U.S.A. At the end of the project phase in October 1993, the Niedersächsische Staats- und Universitätsbibliothek in Göttingen took over the management from the French national library. About 50.000 records of microform masters from four European countries (France, Great Britain, Germany, and Portugal) had been collected until that time. 
The basic working of EROMM has remained the same since the outset: Each participating library collects data from its own computerised catalogue and from affiliated libraries, converts records into the bibliographic format UNIMARC, and sends them to the host to be filed in the register. From the initial 50.000 records the database has grown to 2.5 million. As early as 1994 the EROMM steering committee decided to include records of digital surrogates, if those were produced for preservation and matched commonly recognised standards. It is difficult to draft such standards in terms of preservation requirements because the digital world with its tremendous speed of development does not easily lend itself to stable definitions. To date, no consensus comparable to standards in preservation microfilming has been reached [6].

The uncertainty about what requirements a digital surrogate must meet in order to be considered a preservation surrogate of archival quality has perhaps been the main reason why the EROMM community was slow in contributing records of digitised works. But this has changed considerably after the turn of the century as libraries became confident that they will be able not only to produce high quality digital surrogates but to keep them accessible and migrate them over time. Today we see a steadily increasing number of this new type of surrogate being recorded every year.

For some time now the tremendous spread of digital technology in libraries has been seen to draw on resources that were previously used for microfilming. The decrease in the number of microform master records contributed by those libraries most active in developing their IT capabilities looked as though the production of preservation microforms was in serious decline. This trend has been reversed, however, since the year 2000 .

Another development is well documented in EROMM statistics: In the last five years, European libraries have recorded more preservation surrogates annually than their American counterparts; i.e. roughly the double number of records. This is not surprising since, in the U.S., attempts to record surrogates predate similar European endeavours by far. This is shown by the fact that American records still make for some $78 \%$ of the total number of records in EROMM. In spite of this weight of the American contribution the works that have been reformatted do by no means reflect a similar proportion. Only some $40 \%$ represent material originally published in the U.S. and only about $50 \%$ are in English language, with a decreasing tendency. Looking only at the language respectively the country of publication of works recorded by European libraries we even notice a clear predominance of French language and France. This is due to the vast and still unparalleled reformatting activities of the Bibliothèque Nationale de France. 
On the Importance of Recording Microforms and Digitised Versions Produced for Preservation on the International Level, with a Focus on Standards

Although the French and British contributions to EROMM will for some time be dominating the other European sources, it is shown by the impressive results of the Dutch Metamorfoze project, that other countries can improve their infrastructure and organisation in preservation reformatting and in recording the processed works. In fact the Netherlands have now almost surpassed the contribution of all German libraries together in contributing more than $11 \%$ of the European share.

I will not speak of countries which are far less organised and not of those, that do not contribute records at all to this international database of reformatted works. A glance at the map on the EROMM homepage will give you some idea. But let me state that nonmember countries are by no means neglected by those cooperating for the common preservation goal. A look at the dozen countries of publication that are ranking at the top in EROMM shows that half of them are non-members. The reasons for this are manyfold, as can be seen from the fact, that some of them are countries in Asia.

\section{SPECIAL FEATURES}

\section{Identifying the original}

One of the basic decisions of the early days has proved to be of utmost importance for the reliability of the international register. This is the principle to give a precise bibliographic description of the original work. Today, most contributing libraries reuse the records created for the originals and reproduce them in their entirety [7]. This gives a sound basis for identifying the original work. Indeed this is a precondition for anyone planning a preservation project and wanting to avoid duplication of work already done elsewhere.

\section{Describing the surrogate}

The bibliographic description of the original work is augmented by the description of the surrogate, its date and place of production and technical features, not to forget the clear indication precisely which original copy has been used. Thus you will find indicated the library that owns the copy and the shelf mark under which it is being kept. A hyperlink is added where there is a digital version readily accessible in the web. It might need no special mention for those familiar with EROMM, but it should be said here for all those, who are not. The EROMM partners who collect records from their respective countries or networks have to make sure that surrogates comply with agreed standards. 


\section{Physical attributes}

It is obvious in the multi-language environment of Europe that we will soon be unable to understand the description of a surrogate if we do not understand languages such as Polish, Finnish or perhaps German. But we want the general characteristics given of a surrogate to continue to be meaningful a long time to come and be understandable without having to bridge language barriers. The solution to this problem was found in using coded information. Codes for describing the physical attributes have been developed first for microforms by the American library community. Similarly, it has been found most useful to have codes describe digital surrogates. This can be done in a way to make you understand something meaningful even a hundred or more years from now when software has gone through generations of continued IT development [8].

When displaying a record in EROMM, codes are replaced by text in English as the most commonly understood language. It would be possible to offer the choice of several languages, but this would entail considerable effort in precise translation. So, for the time being, we have decided to be content with English. But another long-standing wish of cataloguers has finally been fulfilled, namely to relieve them from the arduous task of choosing the correct codes while adhering to their fixed character positions. Cataloguers can now make a quick choice from standardised designations. When sending off this choice, the codes will display on screen, ready for pasting them to the window of their respective cataloguing software [9].

\section{Requesting copies or information}

EROMM receives and processes records derived from hundreds of libraries worldwide that do not cooperate with EROMM directly, but are represented by fourteen direct EROMM Partners [10], as well as the Research Libraries Group (RLG) and the Latin American Register of Microform Masters. In spite of this complex background it is possible to use the database as a medium for sending requests directly to those libraries. To achieve this, EROMM had to invest considerable effort in identifying e-mail addresses and other information needed to contact libraries. The result is strikingly simple and effective. When viewing a record in EROMM, librarians may click the request button to ask the owner of the surrogate about technical details or prices or to place a direct order for a copy. By sending the request the system generates two e-mails, one to the owner of the surrogate and another to the requesting library to enable it to keep track of the request. Any further exchanges relating to this request are done bilaterally. 
On the Importance of Recording Microforms and Digitised Versions Produced for Preservation on the International Level, with a Focus on Standards

\section{Reporting ongoing projects}

One of the priorities of EROMM is to help avoid duplication of effort. In order to do this, we try to collect as much information on reformatted printed works as possible. It is equally important to learn about planned reformatting because a lot of effort goes into the preparatory stages of a project. No resources should be lost by discovering too late that the item in question has meanwhile been processed elsewhere. However, in many cases it may not be possible to supply records to EROMM that describe individual items before they are actually digitised or microfilmed.

To alleviate this problem, EROMM provides the option to record the reformatting project itself at an early stage. Simply by giving notice of the project and perhaps by naming authors and titles of the most important works earmarked for reformatting, you can assure that your ongoing project will become retrievable in the EROMM database. From there contact can then be established between projects and others interested [11].

\section{Outlook}

There are two obvious goals set for further development: The inclusion of records from more countries, and the further increase in number and quality of the records of preservation surrogates.

Less visible, but of equal importance, is EROMM's aim to improve cooperation with libraries and to raise awareness of the fact that preservation by reformatting is of no value at all unless access to the surrogate is provided within a reasonably short time and at acceptable cost. There is still much ground to be covered in this field and I believe that it must be seen as a never-ending task [12].

More concrete tasks lying ahead are the migration of the database to new hardware and to an entirely new generation of software. This is tied to overall developments at the host site and is helping EROMM to keep up with modern developments in library software. Intimately connected with this is the task of updating and improving the requesting facility.

In fact, only if copies of surrogates and online access to digital versions are in great demand it can be expected that those owning the surrogates will maintain their holdings in a proper state. A forgotten surrogate is as good - or bad - as a lost surrogate. EROMM provides the tool for bringing to light what has already been done to preserve the printed heritage and to give notice of ongoing activities. 


\section{NOTES}

1. Hartmut Weber, director of the German federal archives, has aptly outlined this problem in his article "Digitalisierung und Bestandserhaltung", published in:

"Wettlauf mit der Zeit - Bestandserhaltung in wissenschaftlichen Bibliotheken", Wiesbaden (1998) p. 37-50. His article is now available at http://www.unimuenster.de/Forum-Bestandserhaltung/konversion/digi-weber.shtml (last visited 31 March 2003).

2. Thus more than a decade and a half ago the wealth of microform holdings in the United States became visible through detailed records held by the library information networks of the RLG and OCLC.

3. It is impossible here to list all the important and very successful projects, which the European Commission on Preservation and Access has supported morally and financially throughout those years. The CPA has meanwhile merged with other agencies to form the CLIR.

4. Nicholson Baker's article "Discards" (New Yorker, 4 April 1994, pp. 64-70+) has harshly criticised this and has provoked numerous reactions. Read a recent article written by Richard J. Cox; "The Great Newspaper Caper: Backlash in the Digital Age" (First Monday, volume 5, number 12, December 2000 at http://firstmonday.org/issues/issue5_12/cox/index.html; last visited 31 March 2003).

5. This reluctant attitude is at times gaining support from another direction, namely that using microforms is not very popular among library users. Some polemic statements and even outright attacks on library preservation programmes challenged the well established fact that silver halide microform on polyester base can last considerably longer than any paper original. Articles in well distributed periodicals can indeed pose a serious threat to reformatting programmes, because they tend to discourage funding bodies from continuing their support. See note 5.

6. Standards are listed on the EROMM website at http://www.eromm.org/standards.htm

7. Regrettably this has not been the case for all early contributers.

8. EROMM took part in a working group set up by the RLG to devise such codes, which were finally introduced in MARC21 \#007 for computer files. Subsequently they were adopted unchanged for UNIMARC.

9. Go to http://www.eromm.org/input/codes-e.htm. This support is offered for the three most commonly applied bibliographic formats.

10. See the list at http://www.eromm.org/input/erompa.htm. 
On the Importance of Recording Microforms and Digitised Versions Produced for Preservation on the International Level, with a Focus on Standards

11. This is done by using hyperlinks in the record. The service is freely available on the EROMM website at http://www.eromm.org/input/ and is not limited to any kind of membership.

12. Needless to say that in trying to raise awareness and advocate the adherence to standards the entire EROMM community is involved. There is nothing like a powerful central administration, instead all achievements in the past and in future rely on cooperation among the EROMM partners and on their respective initiatives in their own countries.

\section{REFERENCES}

National Register of Microform Masters / Library of Congress; American Library Association; Association of Research Libraries. - Washington, DC : LoC, 1965-1984. ISSN: 0090-3299

\section{WEB SITES REFERRED TO IN THE TEXT}

The Andrew W. Mellon Foundation. http://www.mellon.org/

Bibliothèque Nationale de France. http://www.bnf.fr/

Counsel on Library and Information Resources (CLIR). http://www.clir.org/

European Register of Microform Masters (EROMM). http://www.eromm.org/

Metamorfoze. http://www.kb.nl/coop/metamorfoze/home.html

Niedersächsische Staats- und Universitätsbibliothek in Göttingen. http://www.sub.unigoettingen.de/index.html

Research Libraries Group (RLG). http://www.rlg.org/ 